\title{
Controlled-analysis of the effects of inhaled lignocaine in exercise-induced asthma
}

\author{
MARILYN P GRIFFIN, ER McFADDEN jun, RH INGRAM jun, STEPHEN PARDEE \\ From the Shipley Institute of Medicine and the Departments of Medicine of the Brigham and Women's \\ Hospital and Harvard Medical School, Boston, Massachusetts
}

ABSTRACT To determine whether anaesthesia of the intrathoracic airways would attenuate the development of exercise-induced asthma, we studied eight symptomless asthmatic patients by cycle ergometry after saline or lignocaine pretreatment while they were breathing air at $24^{\circ} \mathrm{C}$ with $9 \cdot 1 \mathrm{mg}$ of $\mathrm{H}_{2} \mathrm{O} / 1$. Pulmonary mechanics were measured before and after the administration of each agent, and again five minutes after cessation of exercise. Sufficient lignocaine was administered to abolish the gag reflex and the cough response to aerosols of citric acid. Before exercise there were no significant differences for any lung function variable between the saline and lignocaine results. Equally, there were no significant differences between these agents for minute ventilation (VE) during exercise (VE lignocaine $=71 \cdot 0 \pm 7 \cdot 4$ (SEM) $1 / \mathrm{min}$; VE saline $67 \cdot 2 \pm 8 \cdot 1$ $1 / \mathrm{min}$;), or in the severity of the subsequent bronchospastic response (for example, the $\mathrm{FEV}_{1}$ with saline was $22.6 \pm 2.9 \%$ decrease, and with lignocaine $23.6 \pm 8.5 \%$ ). Thus these results do not support the idea that there are thermally sensitive neural receptors in intrathoracic airways that play a role in the pathogenesis of exercise-induced asthma.

It has been suggested that the inhalation of lignocaine attenuates the development of the airway obstruction that follows physical exertion in asthmatics, and this phenomenon has been cited as evidence that thermally sensitive neural receptors in the respiratory tract are involved in the pathogenesis of exercise-induced asthma. ${ }^{12}$ Although the part played by sensory nerve endings in the posterior pharynx in the development of obstruction has been challenged, ${ }^{3}$ it has been postulated that thermal receptors may be present in the intrathoracic airways and hence might contribute to the postexercise response. ${ }^{2}$ While this is a plausible hypothesis, it was deduced from a series of studies in which minute ventilation was less after the local anaesthetic. ${ }^{2}$ Since the level of ventilation is a critical determinant of the severity of the bronchospasm in exerciseinduced asthma, ${ }^{4-8}$ this factor alone would have produced discordant results. Consequently, the function and even existence of thermal receptors within the central airways remain unclear. In an attempt to clarify this matter we thought it worthwhile to repeat the above experiments under precisely controlled conditions.

Address for reprint requests: Dr ER McFadden jun, Shipley Institute of Medicine, Brigham and Women's Hospital, 75 Francis Street, Boston, Mass 02115, USA.

\section{Methods}

Eight atopic symptom-free persons, seven women and one man (mean age 24.0 \pm 1.7 (SEM) years), who met the American Thoracic Society's definition of asthma9 (that is, reversible airway disease which is characterised by increased responsiveness to a variety of stimuli) served as our subjects. None of the participants smoked cigarettes, or used medication for their disease on a regular basis. All refrained from taking any treatment for at least 12 hours before any study day. Informed consent was obtained from each individual.

Measurements of airway resistance and of total lung capacity and its subdivisions were carried out in a constant-volume, variable-pressure plethysmograph. ${ }^{1011}$ Resistance was converted to its reciprocal, conductance, and expressed as a ratio of conductance to volume - that is, specific conductance (sGaw). The mean of four or five measurements of each variable, whose coefficients of variation were $5 \%$ or less, was computed. After completion of these measurements the subjects performed three maximum forced exhalations into a waterless spirometer. One-second forced expiratory volume was determined by standard techniques. Each subject's best effort, as defined by the curve with the 
largest forced vital capacity and $\mathrm{FEV}_{1}$, was used for analysis.

Inspired gas temperature and water content were controlled by having the subjects breathe through a heat exchanger in series with a bubble humidifier as previously described. ${ }^{512}$ In this instance, the temperatures of the water bath of the humidifier and the heat exchanger were set to duplicate usual ambient laboratory conditions - that is, $23-24^{\circ} \mathrm{C}$ and $9-10$ mg $\mathrm{H}_{2} \mathrm{O} / \mathrm{l} \mathrm{air.}^{35}$ The temperature of the inspired air was continuously recorded by a thermocouple within the exchanger and the water content was verified by passing known volumes of gas through glass drying tubes containing anhydrous calcium sulphate and recording the change in weight. ${ }^{3512}$ Expired gas was directed away from the exchanger, via a oneway valve, into a Tissot spirometer so that tidal volume and minute ventilation could be recorded.

The test consisted of six minutes of exhausting leg work on an ergometer. The work load was increased over 30 seconds to the maximum level that each subject had been able to sustain for six minutes as determined in a preliminary study. Pulmonary mechanics were measured before and five minutes after cessation of work. Previous experience has shown that this time interval coincides with the maximum response and that this type of work provides reproducible results. ${ }^{412}$ Ventilation was recorded continuously while the subject inhaled through the heat exchanger for five minutes before exercise, during exercise, and for five minutes after completion of the work load. The data from the last minute of the rest and exercise periods were analysed. The work loads, duration of exercise, inspired air conditions, and measurement sequences were held constant for the control and lignocaine trials.

The effects of inhaled lignocaine on pulmonary function and the cough and gag reflexes were determined as follows. Pulmonary mechanics were measured and then the subjects inhaled two breaths of an aerosol of a $10 \%$ solution of citric acid $(2.5 \mathrm{mg}$ breath). After recovery sufficient quantities of a $4 \%$ solution of lignocaine to prevent the effects of the citric acid were then administered to the normally breathing seated subjects with a No 40 DeVilbiss nebuliser that was set at a constant delivery time and pressure. The total quantity given averaged $3 \mathrm{mg} / \mathrm{kg}$. In the process, loss of the gag reflex was documented by touching the posterior pharynx with a tongue blade. Pulmonary mechanics were immediately remeasured. Since each subject complained of chest discomfort, and altered his or her lung function after the inhalation of the local anaesthetic, we waited 10-15 minutes until these changes disappeared. At that time we again confirmed the absence of the gag and cough reflex with the appropriate stimuli, and did repeat measurements of pulmonary mechanics. On completion of the latter the subjects underwent the exercise challenge described above. The last set of lung function studies served as the baseline for the test. In the control experiment normal saline was administered. The order of study was randomly क decided. Immediately after exercise the subjects $\overrightarrow{0}$ were re-examined to determine whether the gag reflex was present. Citric acid was not re- $\vec{\omega}$ administered since we had no way of controlling any potential interaction that might occur with the bron- $\vec{x}$ choconstriction induced by physical exertion. Instead, on a separate occasion, we determined the $\vec{\circ}$ duration of effect of lignocaine on the cough and gag reflexes and the pattern of recovery. In keeping with $\doteq$ the findings of previous studies in animals and 0 man, ${ }^{1314}$ the anaesthesia persisted for 20 minutes or $\overrightarrow{-}$ more. Equally important, both reflexes were 0 abolished and recovered together; thus we could simply test one of them after exercise and obtain $\underset{\mathbb{\Phi}}{\mathscr{D}}$ information about both.

The data were analysed by paired $t$ tests and a $\vec{\oplus}$ two-way analysis of variance.

\section{Results}

The prechallenge pulmonary mechanics are shown in figure 1. There were no significant differences between the saline and lignocaine studies in the baseline values for any variable (sGaw saline $=1.69$ $\pm 0 \cdot 1(\mathrm{SEM}) \mathrm{s}^{-1} \mathrm{kPa}^{-1}$; lignocaine $=1 \cdot 5 \pm 0.1 \mathrm{~s}^{-1}$ $\mathrm{kPa}^{-1} ; \mathrm{FEV}_{1}$ saline $=2.78 \pm 0.29 \mathrm{l}$; lignocaine $=$ 䒿 $2.80 \pm 0.31 \mathrm{l}$; and residual volume (RV) saline $=$ $1.59 \pm 0.181$; lignocaine $=1.69 \pm 0.171)$. Equally important, there were no differences in mechanics $\underset{x}{\stackrel{x}{x}}$ before exercise. The inhalation of lignocaine pro- $\dot{\sigma}$ duced an immediate and statistically significant re- 3 duction in $\mathrm{FEV}_{1}$ of $0.43 \pm 0.111(\mathrm{p}<0.01)$, which 8 resolved before challenge.

In the exercise experiments, the mean work load 9 was $107.3 \pm 12.3$ watts. Minute ventilation aver- $>$ aged $67 \cdot 2 \pm 8 \cdot 1 \mathrm{l} / \mathrm{min}$ with saline and $71 \cdot 0 \pm 7 \cdot 4$ 을 $1 / \mathrm{min}$ with lignocaine. The mean inspired air $\overline{\mathrm{N}}$ temperatures were $23.9 \pm 0.5$ and $24.0 \pm 0.5^{\circ} \mathrm{C}^{\circ}$ with saline and lignocaine respectively, and the in- $N$ spired water content was $9 \cdot 1 \pm 0.1 \mathrm{mg} / 1$ of air for $\underset{\omega}{N}$ both studies. There were no significant differences 0 between lignocaine or saline for any variable (figure ${ }_{0}$ 2). The gag and cough reflexes were abolished prior $\mathbb{\mathbb { D }}$ to exercise.

The effects of exercise with and without local 0 anaesthesia are compared in figure 3 . In the saline experiment, sGaw and FEV, fell an average of $45 \cdot 3 \stackrel{\mathbb{\Omega}}{\Omega}$ \pm 4.9 and $22.6 \pm 2.9 \%$ from their pre-exercise $\mathbb{Q}$ values, respectively, while RV rose $41 \cdot 6 \pm 7 \cdot 6 \%$. As can be seen, lignocaine had no effect upon this res- 

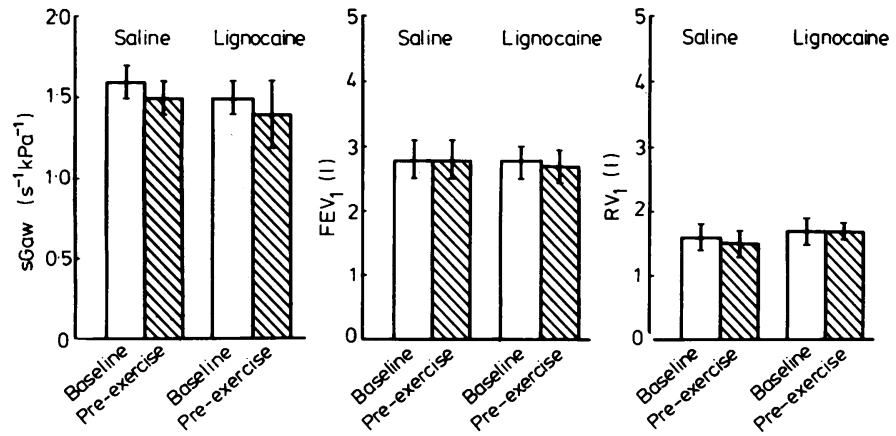

Fig 1 Baseline and pre-exercise lung function with saline and lignocaine.

The heights of the columns represent mean values and the bars one standard error. sGaw - specific conductance; FEV —one-second expiratory volume; $R V-$ residual volume. None of the differences reaches significance.
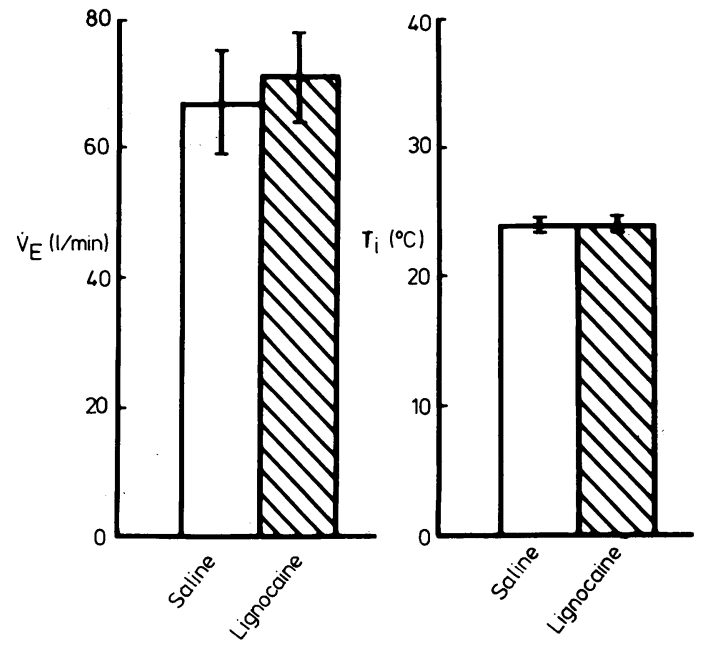

Fig 2 Comparison of minute ventilation $(\dot{V} E)$ and inspired air temperatures $\left(T_{i}\right)$ during exercise after the administration of saline and lignocaine. The heights of the bars represent mean values and the brackets one standard error. The differences do not reach significance.
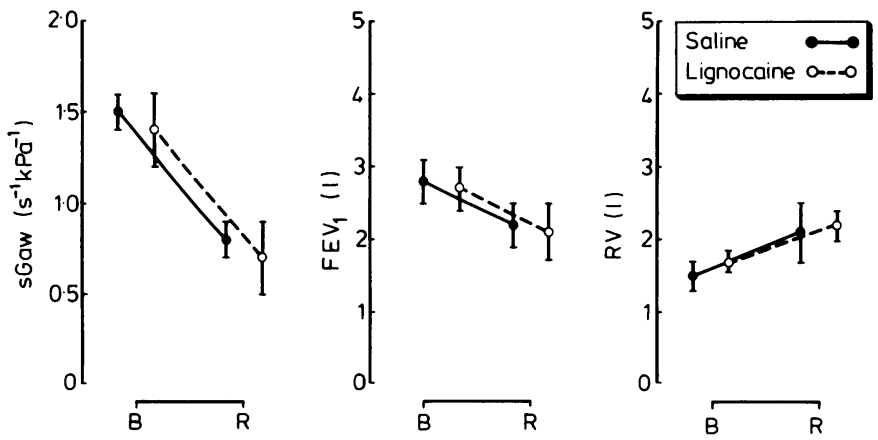

Baseline $(\mathrm{B}) \boldsymbol{v}$ response $(\mathrm{R})$ after exercise:

Saline (S)

Lignocaine (L)

$$
\begin{gathered}
<0.001 \\
<0.005 \\
\text { NS }
\end{gathered}
$$

$$
\begin{gathered}
<0.001 \\
<0.001 \\
\text { NS }
\end{gathered}
$$

$$
\begin{gathered}
<0.001 \\
<0.05 \\
\text { NS }
\end{gathered}
$$

Fig 3 Comparison of the effects of exercise on pulmonary mechanics with and without airway anaesthesia. The data points are mean values and the bars indicate one standard error. Abbreviations as in fig 1. 
ponse. The gag reflex was absent in all instances after exercise in the lignocaine studies.

\section{Discussion}

The data in the present study show that, under controlled conditions, the inhalation of lignocaine does not have any influence on either the obstructive or the ventilatory response to exercise in asthmatics. Since the cough and gag reflexes were abolished before and after challenge, indicating anaesthesia of both extrathoracic and intrathoracic airways, our observations are incompatible with the hypothesis that thermally sensitive neural receptors in the respiratory tract are important in the pathogenesis of exercise-induced bronchospasm or in the control of ventilation during physical exertion.

Our current findings confirm and extend previous work from this laboratory in which eucapnic hyperpnoea was used as the mechanism of inducing airway cooling in the presence of oropharyngeal anaesthesia, ${ }^{3}$ and they are similar to the results of Chen and Chai. ${ }^{15}$ These investigators administered aerosols of distilled water and lignocaine $(1.5 \mathrm{mg} /$ $\mathrm{kg}$ ) to seven asthmatic subjects before treadmill exercise and did not find any difference in the subsequent severity of the airway obstruction.

These two sets of observations are at variance with those of Enright et al, ${ }^{2}$ who found that pretreatment with lignocaine significantly reduced the development of exercise-induced asthma and so concluded that "mucosal receptors" were directly involved in the initiation of this phenomenon. Nevertheless, as we pointed out earlier, since VंE was materially less after the local anaesthetic in their study, and since this factor alone would have reduced the degree of airway cooling and so the severity of the response, ${ }^{3-58}$ there was no way of determining whether the smaller response was due to a lesser stimulus. The similar ventilations in the control and lignocaine trials in the current work removes this ambiguity and would isolate any possible reflex effect. In this way the design of the study makes it probable that in the previous work respiratory heat loss was the major stimulus and that the development of airway obstruction did not depend on the stimulation of sensory receptors.

In the study of Enright and associates ${ }^{2}$ it is not clear why $\dot{V} E$ during exercise after anaesthesia did not reach the same value as that seen with saline. While it has been shown that local anaesthetics do not modify the severity of induced bronchoconstriction $^{16}$ or affect the breathing pattern of normal subjects, ${ }^{14} 17$ those drugs can decrease the inspiratory drive associated with airflow obstruction and so prevent $\dot{V}_{E}$ from rising to the level it would have. otherwise reached. ${ }^{17}$ This effect, however, is usually $\underset{\frac{\mid}{\sigma}}{\stackrel{7}{O}}$ small. If this factor was in operation and the lig- 듬 nocaine also increased airway resistance substan- $-\frac{\bar{c}}{\overline{0}}$ tially, as it did in our study, and if this was not per- $\bar{\Phi}$ mitted to resolve, then it is conceivable that $\stackrel{\circ}{\circ}$ increased obstruction could have resulted in a leng- $-\hat{\infty}$ thened time of inspiration and reduced mean $\vec{O}$ inspiratory flows sufficiently to have affected $\dot{V} E$ during exercise. We would not have observed this $\vec{\rho}$ phenomenon in our study since we ensured that the acute constrictor effects of lignocaine had resolved before challenge.

Whatever the reasons for the differences in venti- $\overrightarrow{0}$ lation, the results of the present study do not sup-

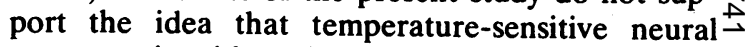
receptors in either the posterior pharynx or the $\frac{\text { o }}{5}$ intrathoracic airways play a part in the production of $\rightarrow$ exercise-induced bronchospasm or the regulation of $O$ ventilation during exercise. Rather the studies pur- $\stackrel{0}{0}$ porting to show such effects appear to have drawn their conclusions from experiments in which differ- ences in respiratory heat loss could explain their $\infty$ results.

\section{References}

' McNally JF, Enright P, Hirsch JE, Souhrada JF. The $\overrightarrow{\overrightarrow{0}}$ attenuation of exercise-induced bronchoconstriction 3 by oropharyngeal anaesthesia. Am Rev Respir Dis 1979;119:247-52.

${ }^{2}$ Enright PL, McNally JF, Souhrada JF. Effect of lidocaine on the ventilatory and airway responses to $\overrightarrow{\mathrm{O}}$

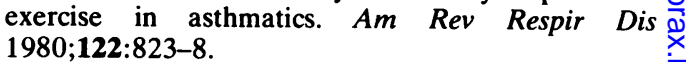

${ }^{3}$ Fanta CH, Ingram RH Jr, McFadden ER Jr. A $\frac{\bar{\sigma}}{3}$ reassessment of the effects of oropharyngeal anesthesia in exercise-induced asthma. Am Rev Respir Dis 1980;122:381-6.

${ }^{4}$ Deal EC Jr, McFadden ER Jr, Ingram RH, Strauss RH, 을 Jaeger JJ. Role of respiratory heat exchange in pro- $D$ duction of exercise-induced asthma. J Appl Physiol: 을. Respir Environ Exercise Physiol 1979;46:467-75.

${ }^{5}$ Deal EC Jr, McFadden ER Jr, Ingram RH Jr, Jaeger JJ. O Hyperpnea and heat flux: initial reaction sequence in $\mathrm{N}$ exercise-induced asthma.J Appl Physiol: Respir Envi- N ron Exercise Physiol 1979;46:476-83.

$\therefore$ Kilham H, Tooley M, Silverman M. Running, walking and hyperventilation causing asthma in children. Thorax 1979;34:582-6.

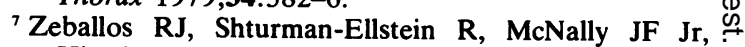
Hirsch JE, Souhrada JF. The role of hyperventilation 0 in exercise-induced bronchoconstriction. $A m \operatorname{Rev}$ 응 Respir Dis 1978;118:877-84.

${ }^{8}$ Resnick AD, Deal EC Jr, Ingram RH Jr, McFadden ER $\frac{\rho}{\Phi}$ Jr. A critical assessment of the mechanism by which $\varrho$ hyperoxia attenuates exercise-induced asthma. J Clin Invest 1979;64:541-9. 
${ }^{9}$ American Thoracic Society. Definition and classification of chronic bronchitis, asthma, and pulmonary emphysema. Am Rev Respir Dis 1962;85:762-8.

${ }^{10}$ DuBois AB, Botelho SY, Bedell GN, Marshall R, Comroe JH Jr. A rapid plethysmographic method for measuring thoracic gas volume: a comparison with a nitrogen washout method for measuring functional residual capacity in normal subjects. J Clin Invest 1956;35:322-6.

$"$ DuBois AB, Botelho SY, Comroe JH Jr. A new method for measuring airway resistance in man using a body plethysmograph: values in normal subjects and in patients with respiratory disease. $J$ Clin Invest 1956;35:327-35.

12 Strauss RH, McFadden ER Jr, Ingram RH Jr, Deal EC $\mathrm{Jr}$, Jaeger JJ. Influence of heat and humidity on the airway obstruction induced by exercise in asthma. $J$ Clin Invest 1978;61:433-40.
${ }^{13}$ Dain DS, Boushey HA, Gold WM. Inhibition of respiratory reflexes by local anesthetic aerosols in dogs and rabbits. J Appl Physiol 1975;38:1045-50.

${ }^{14}$ Cross BA, Guz A, Jain SK, Archer S, Stevens J, Reynolds F. The effect of anesthesia on the airway in dog and man: a study of respiratory reflexes, sensations and lung mechanics. Clin Sci Molec Med 1976;50:439-54.

${ }^{15}$ Chen WY, Chai $H$. Effect of inhaled lidocaine on exercise-induced asthma. Physiologist 1981;24:28.

${ }^{16}$ Thompson NC. The effect of different pharmacologic agents on respiratory reflexes in normal and asthmatic subjects. Clin Sci 1979;56:235-41.

17 Savoy J, Fleetham JA, Arnup M-E, Anthonisen NR. Airway anesthesia and respiratory response to methacholine induced bronchoconstriction. Resp Physiol 1981;43:59-68. 